\title{
Study of the elemental composition of saliva of smokers and nonsmokers by $\mathrm{X}$-ray fluorescence
}

\author{
Antônio A. Poles Jr. ${ }^{\mathrm{a}}$, Victor M. Balcão ${ }^{\mathrm{b}, \mathrm{c}}$, Marco V. Chaud ${ }^{\mathrm{b}}$, Marta M.D.C. Vila ${ }^{\mathrm{b}}$, \\ Norberto Aranha ${ }^{\mathrm{a}}$, Valquíria M.H. Yoshida ${ }^{\mathrm{b}}$, José M. Oliveira Jr. ${ }^{\mathrm{a}, *}$ \\ a LaFINAU - Laboratory of Applied Nuclear Physics of University of Sorocaba, University of Sorocaba - UNISO, 18023-000 Sorocaba/SP, Brazil \\ ${ }^{\mathrm{b}}$ LaBNUS - Laboratory of Biomaterials and Nanotechnology of the University of Sorocaba, i(bs) ${ }^{2}-$ Intelligent Biosensing and Biomolecule Stabilization \\ Research Group, Technological Park of Sorocaba, 18078-005 Sorocaba/SP, Brazil \\ ${ }^{\mathrm{c}} \mathrm{CEB}$ - Centre of Biological Engineering, University of Minho, Braga, Portugal
}

\section{A R T I C L E I N F O}

\section{Keywords:}

$\mathrm{X}$-ray fluorescence analysis

Saliva

Tobacco

Male and female smokers

\begin{abstract}
A B S T R A C T
Cigarette smoking is a serious public health problem. According to data from the World Health Organization, it is estimated that currently more than 1.2 billion people worldwide do tobacco use and that smoking-related diseases are responsible for about 6 million deaths each. With attention to this, it is necessary to seek preventive and prognostic of trying to reduce these numbers and alert the public in general about the danger and the harm caused by its use. Thus, the objective of the research work undertaken was to evaluate and compare the chemical composition of collected saliva samples of smokers and nonsmokers by X-ray Fluorescence analyses. 32 individuals were selected, 16 of which used cigarette on a daily basis and the other 16 had never smoked. Saliva was collected with the help of a (sterile) disposable Pasteur pipette and samples sent to the Applied Nuclear Physics Laboratory at UNISO (LAFINAU), where analyzes were carried out. Individuals who agreed to participate in the study answered a questionnaire to define their profile of inclusion and signed an informed consent form (CEP Protocol no. 831.753 of 09/10/2014). The results clearly showed that there are differences in the concentrations of chemical elements in the saliva of smokers and non-smokers. The biggest discrepancies were found at concentrations of the chemical elements Sulfur, Phosphorus, Chlorine and Potassium, and smaller differences in the concentration of the elements Calcium, Manganese, Iron, Copper, Titanium, Vanadium and Nickel. In only one saliva sample, and in quite low amounts, arsenic was detected. The results indicate that smoking produces more significant changes in the saliva of women than in men, increasing the concentration of some elements in the saliva of female smokers, much more than in the male smokers. The cigarette usage time also appears to exert a greater influence on the composition of the saliva of women than in men, indicating that the damage caused by cigarette use may in fact be higher in women than in men.
\end{abstract}

\section{Introduction}

In the cigarette there are numerous potentially toxic chemical substances. It is believed that more than a thousand components of carcinogens and toxic gases and metals (Gunnerbeck et al., 2014) are present in tobacco. When swallowed, tobacco smoke is inhaled into the lungs, which have a large blood flow, allowing such deleterious substances to pass the alveolar barrier and, after approximately $10 \mathrm{~s}$, they are distributed by the circulatory system and reach the brain. This speed in only to be compared with an intravenous application of medication (Rang et al., 2007). The main component of tobacco that causes addiction is nicotine, found in all tobacco derivatives, which is a psychoactive substance that acts in the accumbens nucleus in the central nervous system, a region that, when stimulated, defers sense of pleasure, which explains the satisfaction that tobacco smoke imparts to the smoker. With the continuous and prolonged consumption of nicotine, the brain adapts and begins to need increasing doses to maintain the same level of satisfaction that the smoker had at the beginning. This effect is called tolerance to the drug. Over time, the smoker needs to consume more and more cigarettes (Rang et al., 2007). This chronic exposure to various chemical compounds is responsible for the diseases associated with the smoking habit. According to World Health Organization (WHO) data, $30 \%$ of all cancer deaths are directly related to smoking, as well as $90 \%$ of lung cancer. In addition, acute myocardial infarction, stroke, hypertension, and especially their own airway disease, such as Chronic Obstructive

\footnotetext{
* Correspondence to: Universidade de Sorocaba (UNISO), Cidade Universitária Prof. Aldo Vannucchi, Rod. Raposo Tavares km 92.5, CEP 18023-000 Sorocaba/SP, São Paulo, Brazil.

E-mail address: jose.oliveira@prof.uniso.br (J.M. Oliveira).
} 
Pulmonary Disease (COPD). More than 85\% of COPD patients were diagnosed with, or are still, smoking (WHO, 2016; Rang et al., 2007). The saliva is one of the more versatile and complex fluids present in the human body, playing an important role in chewing and in the lubrication of both mouth and pharynx, being responsible for the preservation of oral health. Approximately $99.5 \%$ of saliva is water, with the remaining components being organic and inorganic molecules, a composition that may vary either from one individual to another or even for the same individual throughout the day (Sánchez et al., 2008; Lima et al., 2008; Edgar, 1992; Abraham et al., 2010; Cleto, 2013). The need to quantify chemical elements present in biological fluids has led to the development of analytical techniques aiming at a rapid and accurate analysis, such as X-Ray Fluorescence (XRF) analysis. The XRF and its variants (EDXRF and TXRF) have been used for elemental analysis, in various areas of knowledge (Melquiades et al., 2011; Marguí et al., 2009; Zamburlini et al., 2007; Kajiya et al., 2014; Zamboni et al., 2015; Castilhos et al., 2015). In the research work entertained herein, the analytical technique known as Energy Dispersive X-Ray Fluorescence (EDXRF) (Nascimento, 1999; Parreira, 2006) was used to analyze the oral fluids. Abraham et al. (2010), Sanchez et al. (2008) and Cleto (2013) analyzed saliva samples using a similar (although more accurate) technique to EDXRF, called Total Reflection X-Ray Fluorescence (TXRF), to identify the different components present in saliva. The concentration of oligoelements in saliva or gingival crevice fluid is affected by smoking, mainly through the action of proteins and/or changes in the $\mathrm{pH}$ of these fluids. Taking into account that oligoelements are bioavailable forms of trace minerals that are rapidly absorbed sublingually and that these oligoelements unlock the various metabolic processes which generate functional or infectious diseases, these bioavailable elements work by normalizing enzyme and hormonal functions in order to regulate homeostasis in the body. As cigarettes can produce changes in the concentration of these oligoelements, tobacco smoke can make the smoker more susceptible to diseases. Many other side effects of smoking can be observed as a result of the aggression suffered by the oral environment (Abraham et al., 2010). In this research work the analytical technique EDXRF was used to analyze the oral fluids of 32 individuals, randomly chosen among smokers and nonsmokers of both genders. The elemental concentrations in such oral fluids were measured, and the differences between the mean values of the groups (smokers and nonsmokers of both genders) were duly evaluated.

\section{Materials and methods}

The X-ray Fluorescence Technique (XRF) consists in the emission of characteristic X-rays from a material that has been excited via bombardment with either high-energy X-rays or gamma rays. Because each element has a unique set of atomic energy levels, it emits a unique set of X-rays, which are characteristic of such element. Hence, the presence of characteristic X-rays directly indicates the presence of a given element. Moreover, the intensity of an X-ray line depends on the number of corresponding atoms which were excited, allowing the identification and quantification of the chemical elements present in a sample. The laboratory setup used in this research work is shown in Fig. 1. It included: a) an Amptek (Bedford, Massachusetts, USA) $25 \mathrm{~mm}^{2}$ SDD X-ray detector with a resolution of $128 \mathrm{eV}$ at the Mn $\mathrm{Ka}$ line; b) an X-ray tube with a W anode, manufactured by Hamamatsu Photonics K.K., model L-6731-01 (Hamamatsu Photonics K.K., Japan) and set up to work at $25 \mathrm{kV}, 100 \mu \mathrm{A}$, and using an Al filter with $150 \mu \mathrm{m}$ thickness. Additionally, Amptek's ADMCA software for data acquisition and control of the signal processor and Amptek's XRS-FP ${ }^{\mathrm{TM}}$ software for spectrum processing and quantitative analysis were utilized. With this experimental apparatus, it was possible to detect and quantify various chemical elements with atomic number from magnesium upwards.

The methodology used was based on the random selection of 32 individuals of both genders, of which 16 individuals made use of $20 \pm 5$ cigarettes on a daily basis and 16 individuals had never (actively) smoked. These individuals were 16 males and 16 females, divided in 8 smokers and 8 non-smokers in each group. Three times a day, about $10 \mathrm{ml}$ of saliva was collected with the help of a sterile disposable Pasteur pipette, poured into a plastic container made of polyethylene and forwarded to the Applied Nuclear Physics Laboratory of UNISO (LAFINAU), where all the analyses were carried out, in the period of up to $3 \mathrm{~h}$ of being collected, via the EDXRF setup displayed in Fig. 1. Throughout the day, at least three saliva samples from each individual were collected, which were then pooled and considered as a representative sample for that individual, for subsequent analysis by X-ray fluorescence. All fluorescence measurements were made in triplicate $(\mathrm{n}=3)$. For all comparisons made in this study, an ANOVA statistical analysis was performed, adopting a significance level of $5 \%(\mathrm{p} \leq 0.05)$ and the results were expressed as mean \pm standard deviation. Individuals who agreed to participate in the study previously answered a questionnaire to define the profile of inclusion into the study and freely signed an informed consent. All analyses were carried out using atmospheric air, and the measuring time was set at $1800 \mathrm{~s}$ (live time) for each sample. The XRF system was calibrated through the use of standardized and control samples. The control samples were produced in LAFINAU, using chemical elements with different concentrations, dissolved in high-purity ultrapure water, obtained via purification in a Milli-Q ${ }^{\circledR}$ system (Molsheim, France). Samples were made with the same chemical elements which were intended to be measured in (real) saliva samples, in order to calibrate the detection system and obtain the minimum detectable limits (MDL) to the chemical elements of interest. The control samples were produced with at least 3 different concentrations, for each of the chemical elements $\mathrm{P}, \mathrm{S}, \mathrm{Cl}, \mathrm{K}, \mathrm{Ca}, \mathrm{Cr}, \mathrm{Mn}, \mathrm{Fe}, \mathrm{Ni}$ and $\mathrm{Cu}$. Saliva samples were kept in a sample holder made of polypropylene, a polymer composed of carbon and hydrogen atoms $\left(\left(\mathrm{C}_{3} \mathrm{H}_{6}\right)_{n}\right)$ which, when excited, produce no characteristic X-rays of sufficient energy to be detected by the fluorescence system, hence not interfering with the results of the elemental analysis. It were used as exclusion criteria in this study, individuals who said they were former smokers; people with a chronic disease or some kind of disease in the oral region; those making daily use of medications or who were exposed routinely to toxic agents. In specific for non-smokers, it was considered an exclusion criterion, those who claimed to be indirectly exposed to cigarette smoke regularly (passive smoking).

\section{Results and discussion}

The EDXRF technique was chosen to be used in this research work due to several key advantages over other analytical methods used in analytical chemistry, such as: a) it is a non-destructive analytical procedure, causing no damage to the sample being tested; b) it requires no sample preparation; c) it is a very fast analytical technique (although sensitivity improves with measurement timeframes); and d) it can be carried out quickly by operators with only a minimal training. EDXRF can provide analytical results with an accuracy of a few parts per million $(\mu \mathrm{g} / \mathrm{g})$ and can be used to quantify chemical elements present in a formulation as long as they have an atomic number from element magnesium until fermium $(\mathrm{Z}=100)$. The results were analyzed both qualitatively and quantitatively. Fig. 2 shows the typical spectrum of the saliva of two individuals, one being a smoker and the other being a nonsmoker. The major chemical elements found are pinpointed in Fig. 2. The measured spectra were analyzed with the XRS-FP ${ }^{\mathrm{TM}}$ software package provided by Amptek Inc., taking into account both escape peaks and sum peaks, and representing the background with a polynomial function.

For each reference control sample used in the calibration of the XRF system, calibration curves were constructed, as shown in Fig. 3 for the element calcium. From the linear fitting of the data, the minimum detectable limit for each element was obtained. The curve of minimum 


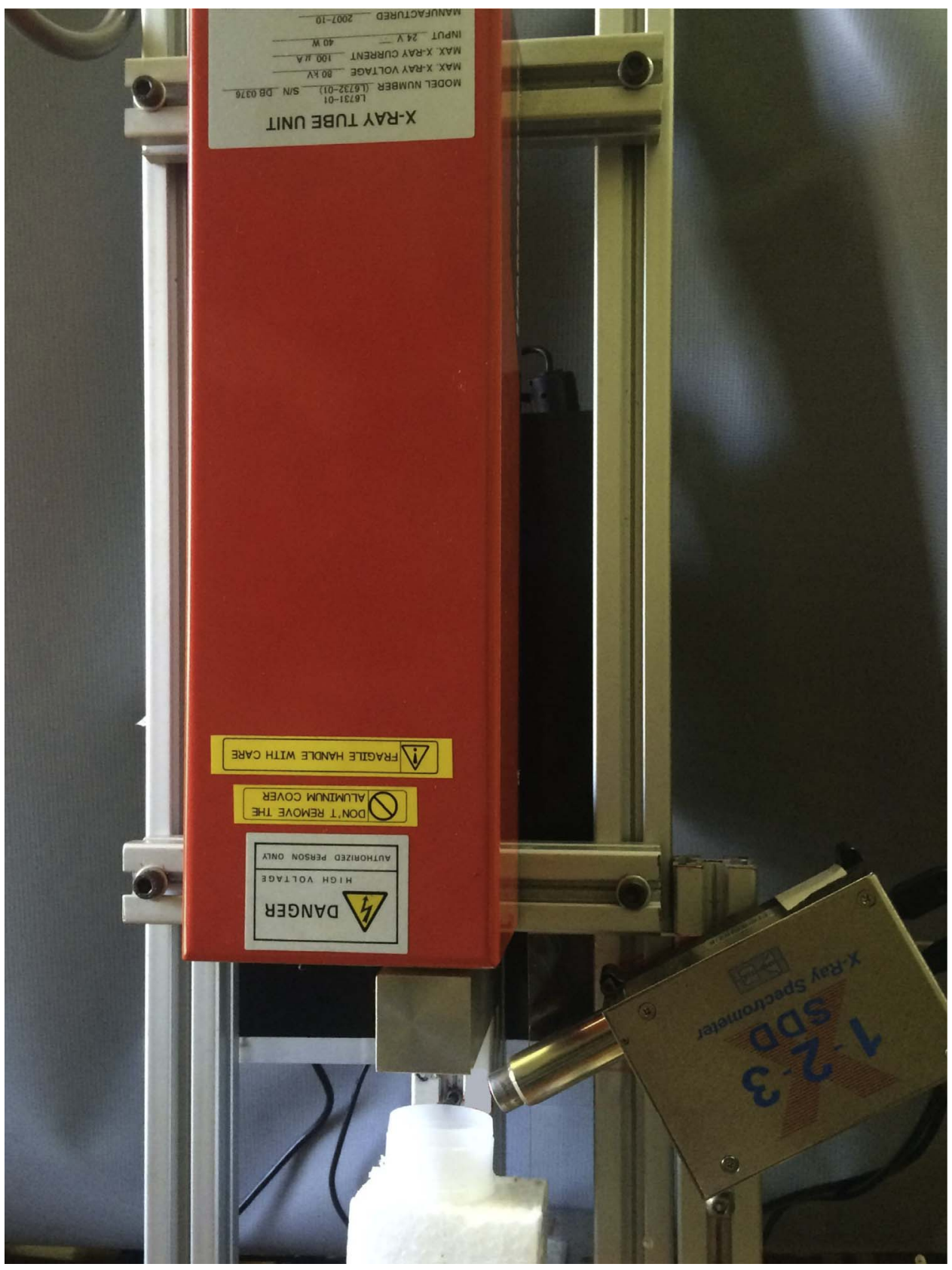

Fig. 1. Image of the X-ray fluorescence setup utilized in the analyses.

detectable limits (MDL) is shown in Fig. 4. This curve allows determination of the sensitivity of the system, in detecting the minimum amounts of the different elements present in saliva. For example, for the element Chromium $(\mathrm{Z}=24)$, sensitivity of the system is of the order of parts per billion (ng/g).

Essentially, the same elements were detected in the XRF spectra of smokers and nonsmokers groups. The main elements detected and quantified were: $\mathrm{S}, \mathrm{P}, \mathrm{Cl}$ and $\mathrm{K}$ in larger quantities and $\mathrm{Ca}, \mathrm{Mn}, \mathrm{Fe}, \mathrm{Cu}$, $\mathrm{Ti}, \mathrm{V}$ and $\mathrm{Ni}$ in minor amounts. In only one sample of non-smoking individual and female and in quite low amounts of $(47 \pm 37) \mu \mathrm{g} / \mathrm{g}$, Arsenic was detected. Figs. 5 and 6 display bar-graphs with the concentrations $(\mu \mathrm{g} / \mathrm{g})$ obtained for the different elements detected, and associated standard deviation bars. The plots show different concentrations of the elements present in the saliva of smokers and nonsmokers, with a tendency for higher values of concentrations of different elements in the saliva of smokers. From the set of 32 individuals that composed the whole frame of the study, 16 were male and 16 were female. However, for each number of cigarettes smoked on a daily basis, the distribution was as follows: 3 individuals smoked 10 cigarettes/day, 2 individuals smoked 15 cigarettes/day, 1 individuals smoked 16 cigarettes/day, 7 individuals smoked 20 cigarettes/day, and 3 individuals smoked 30 cigarettes/day.

Figs. 5 and 6 show that the concentration of the elements $\mathrm{P}, \mathrm{S}, \mathrm{Cl}$ and $\mathrm{K}$ increase with smoking. For the elements that appear in lower concentrations, shown in Fig. 6, namely, $\mathrm{Ca}, \mathrm{Cu}, \mathrm{Fe}, \mathrm{Mn}, \mathrm{Ni}$, Ti and V, smoking seems to interfere less with the concentration of these elements, but on average there is a small increase in the concentration of elements in the saliva of smokers. When we separated the test subjects by sex and analyzed the concentration of different chemical elements present in the saliva of male and female smokers and nonsmokers, differences were found, as shown in Figs. 7 and 8.

Fig. 7 shows that on average the saliva of nonsmokers of both sexes (8 males and 8 females) have concentrations close to one another, with the exception of the $\mathrm{S}$ element, which appears in a higher concentration 


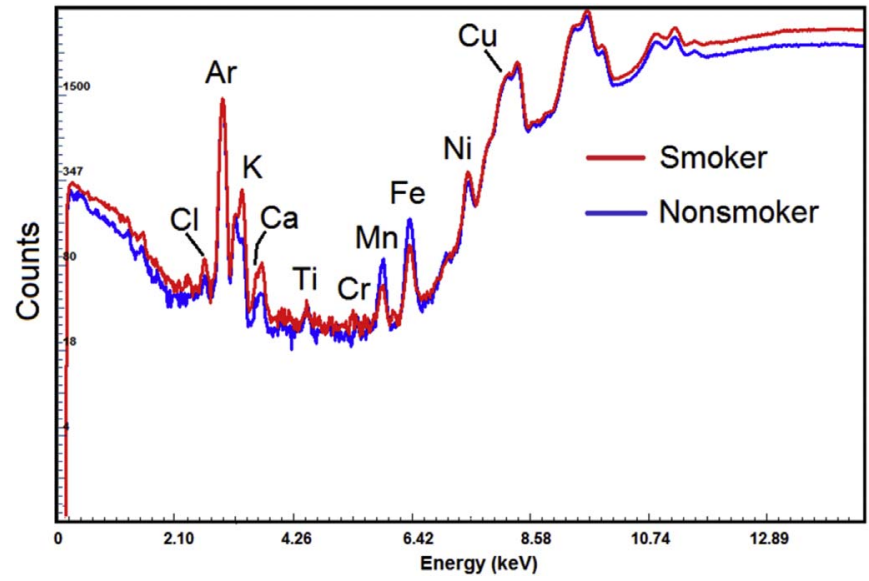

Fig. 2. Typical XRF spectrum of saliva. The red and blue lines correspond to a smoker and nonsmoker individual, respectively. The ordinates axis represents the number of characteristic X-ray counts that reached the detector. The scale used on the abscissa axis is the energy of the characteristic X-rays. (For interpretation of the references to color in this figure legend, the reader is referred to the web version of this article.)

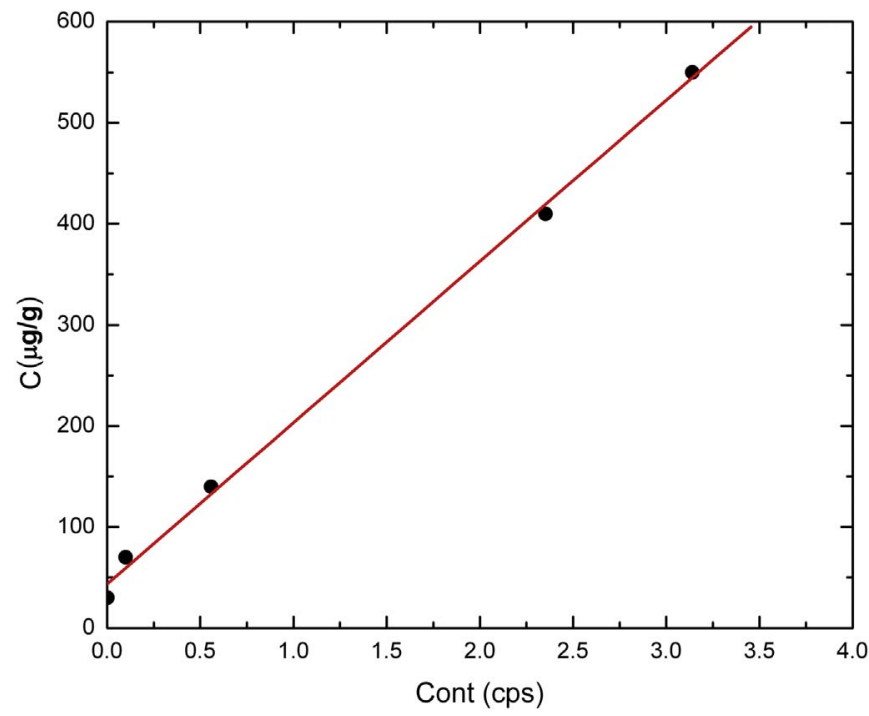

Fig. 3. Calibration curve for the element Calcium. The linear adjust is $\mathrm{C}=43.57+159.61$ Cont, with $\mathrm{R}=9987$. The $\mathrm{MDL}$ for this element is $43.57 \mu \mathrm{g} / \mathrm{g}$. The ordinates axis represents the concentration of calcium in $(\mu \mathrm{g} / \mathrm{g})$ and the abscissa axis is the number of characteristic X-rays (cps) that arriving at the detector.

in the saliva of men. However, looking at Fig. 8, to the higher concentration components $(\mathrm{S}, \mathrm{P}, \mathrm{Cl}$ and $\mathrm{K})$, the increase in concentration is clear from these elements in the saliva of female smokers, indicating that smoking seemed to exert a higher influence in women's saliva composition than in men's. For both groups, the amount of cigarettes smoked per day was the same, viz. $20 \pm 5$ cigarettes/day. Table 1 shows the values found for the concentration of the different elements present in the saliva of smokers $(n=16)$ and nonsmokers $(n=16)$ of both sexes.

The concentration of the different elements present in the saliva of both sexes, as a function of the length of cigarette use (ranging from 3 to 43 years of smoking) and the number of cigarettes smoked per day ( $25 \pm 5$ cigarettes/day), was also analyzed. When the concentration of the chemical elements $(\mathrm{S}, \mathrm{Cl}, \mathrm{K}$ and $\mathrm{Ca}$ ) was analyzed in the saliva of smokers of both sexes, as a function of the time of cigarette use, an increasing trend in the concentration of these elements for females and a decrease for the males was observed, indicating that cigarette smoking seems to be more harmful to women than to men. When the concentration of the main elements present in the saliva of smokers of both sexes was analyzed, according to the number of cigarettes

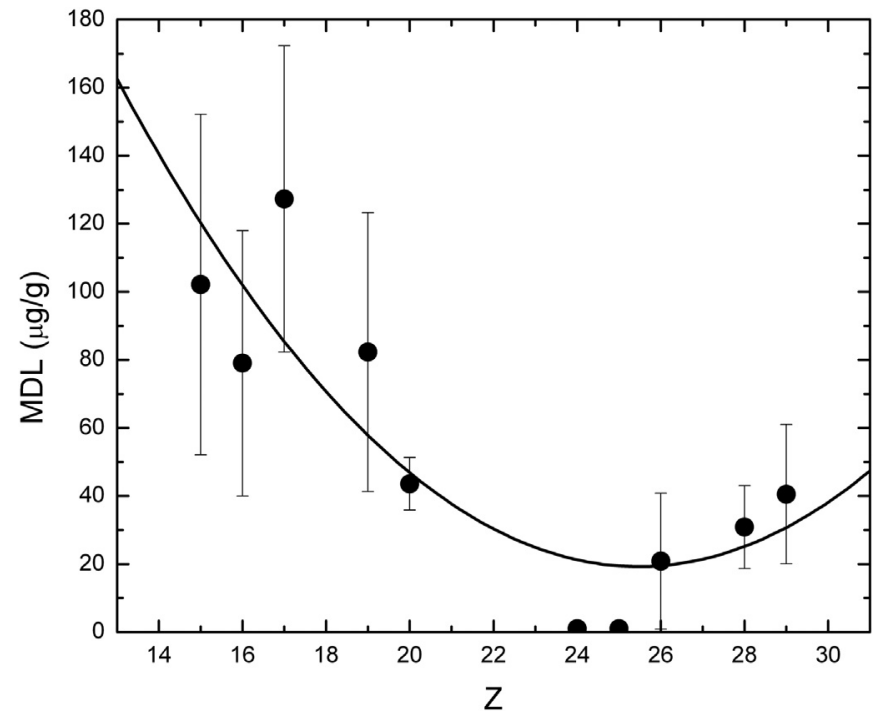

Fig. 4. Minimum detectable limit (MDL) for the chemical elements of interest. The curve was produced via non-linear fitting of a second-degree polynomial function ( $\left.M D L=616.96-46.93 Z+0.9212 Z^{2}, R=0.7537\right)$. The ordinates axis represents the minimum limit detectable in $\mu \mathrm{g} / \mathrm{g}$ and the abscissa axis is the atomic number.

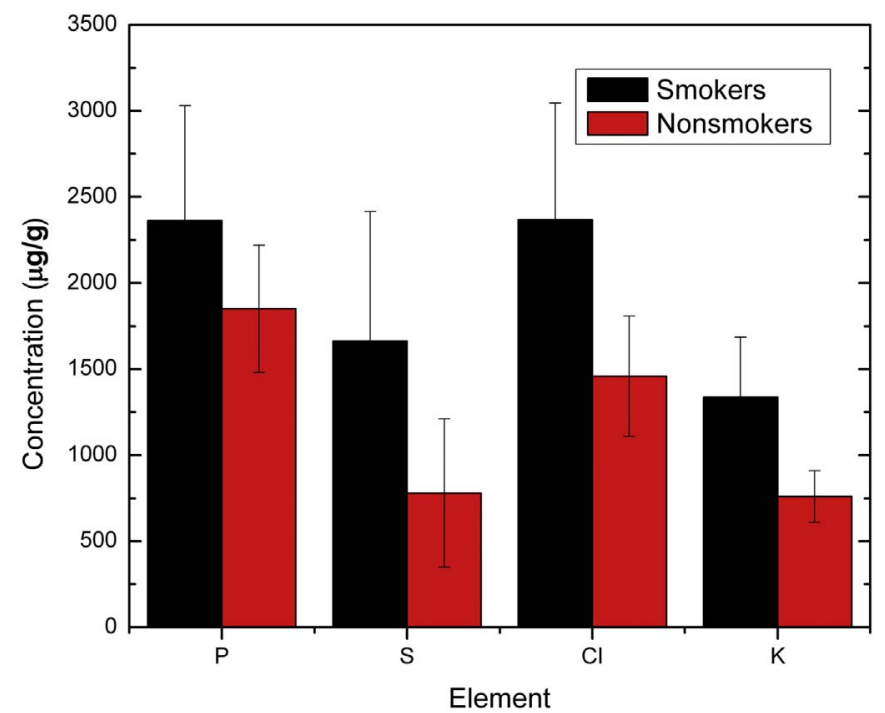

Fig. 5. Bar-graphs with the mean concentration $(\mu \mathrm{g} / \mathrm{g})$ of the different elements detected in higher concentrations in the saliva of smokers and nonsmokers. Standard deviation bars are also included (triplicate measurements for fluorescence analyses for each one of 16 smoker and 16 nonsmoker individuals). Legend: black=smoker and red=nonsmokers. The ANOVA analyses performed for elements $\mathrm{P}, \mathrm{S}, \mathrm{Cl}$, and $\mathrm{K}$ produced the following $p$ values: $\mathrm{P}(p=0.23), \mathrm{S}(p=0.03), \mathrm{Cl}(p=0.02)$ e $\mathrm{K}(p=0.01)$. (For interpretation of the references to color in this figure legend, the reader is referred to the web version of this article.)

smoked over a day, the concentrations tended to decrease for males, as a function of the number of cigarettes smoked per day, much more that the average reduction found for women. As smoking for the general public (male and female), on average, increases the concentration of some chemical elements present in the saliva, the main factor associated with this increase seems to be the time of cigarette use and not the amount of cigarettes smoked per day. Furthermore, all results obtained indicate that smoking seems to be more harmful for females than for males. Figs. 9 and 10 show data obtained in this study compared to data gathered from the literature (Abraham et al., 2010), for the elemental composition of the saliva of smoker and nonsmoker individuals of both genders.

Our data compared with the literature data has shown that, in general, smoker individuals always present higher concentrations for 


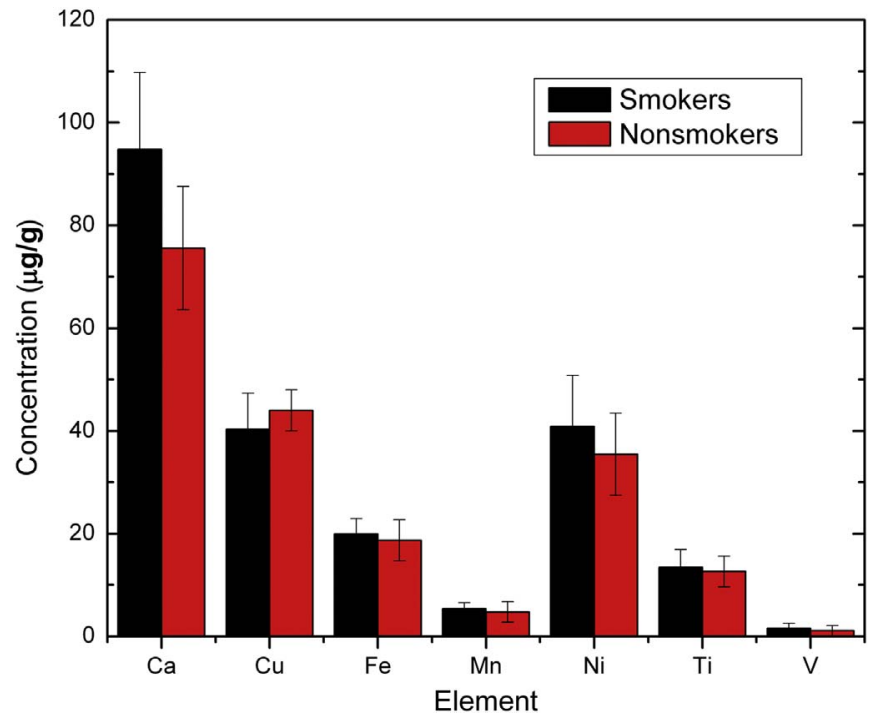

Fig. 6. Bar-graphs with the concentration $(\mu \mathrm{g} / \mathrm{g})$ of the different elements detected in lower concentrations in the saliva of smokers and nonsmokers. Standard deviation bars are also included (triplicate measurements for fluorescence analyses for each one of 16 smoker and 16 nonsmoker individuals). Legend: black=smoker and red=nonsmokers. The ANOVA analyses performed for elements $\mathrm{Ca}, \mathrm{Cu}, \mathrm{Fe}, \mathrm{Mn}, \mathrm{Ni}$, Ti and $\mathrm{V}$ produced the following $p$-values: $\mathrm{Ca}(p=0.03), \mathrm{Cu}(p=0.29), \mathrm{Fe}(p=0.51), \mathrm{Mn}(p=0.32), \mathrm{Ni}(p=0.28)$, Ti $(p=0.71)$ e V $(p=0.50)$. (For interpretation of the references to color in this figure legend, the reader is referred to the web version of this article.)

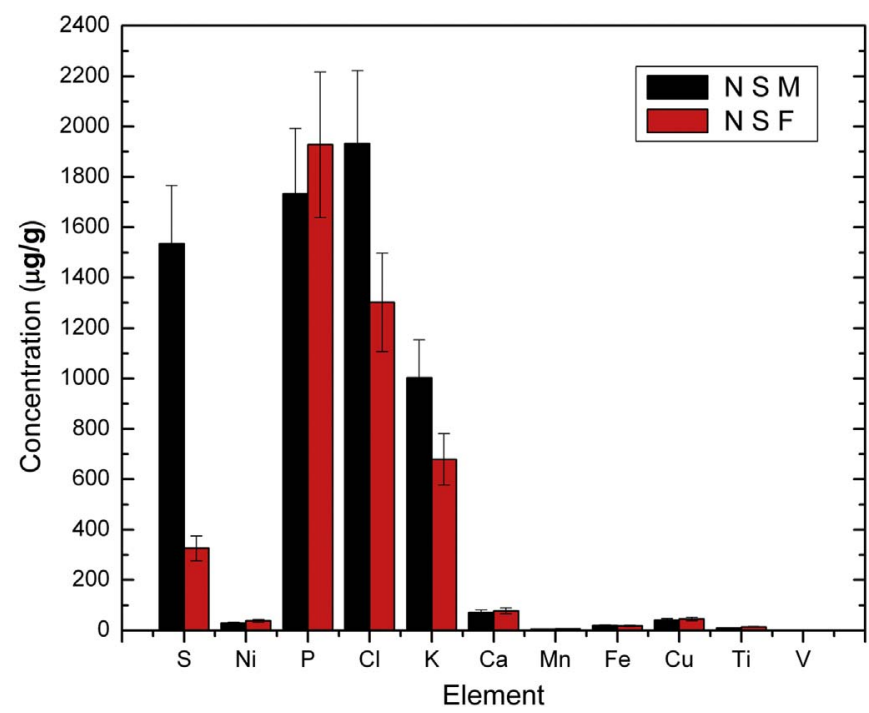

Fig. 7. Bar-graphs with mean concentration $(\mu \mathrm{g} / \mathrm{g})$ of the different chemical elements found in saliva samples from nonsmokers, divided by sex. Standard deviation bars are also included (triplicate measurements for fluorescence analyses for each one of 8 nonsmoker female and 8 nonsmoker male individuals). Legend: black=NSM (nonsmoker male) and red=NSF (nonsmoker female). The ANOVA analyses performed for elements $\mathrm{S}, \mathrm{Ni}, \mathrm{P}, \mathrm{Cl}, \mathrm{K}, \mathrm{Ca}, \mathrm{Mn}, \mathrm{Fe}, \mathrm{Cu}, \mathrm{Ti}$ and V produced the following $p$-values: $\mathrm{S}(p=0.04), \mathrm{Ni}$ $(p=0.28), \mathrm{P}(p=0.81), \mathrm{Cl}(p=0.82), \mathrm{K}(p=0.01), \mathrm{Ca}(p=0.83), \mathrm{Mn}(p=0.32), \mathrm{Fe}(p=0.51)$, $\mathrm{Cu}(p=0.29)$, Ti $(p=0.71)$ e V $(p=0.51)$. (For interpretation of the references to color in this figure legend, the reader is referred to the web version of this article.)

the different chemical elements in their saliva when compared to nonsmoker individuals. For some chemicals elements, the concentration values obtained in this study were the same as those reported in the literature (Abraham et al., 2010), namely for K, Ca, Fe, Cu and Ti for smokers, and $\mathrm{Fe}$ and Ti for nonsmokers, but there are discrepancies in the concentrations of other elements, both for smoking and nonsmoking individuals. Abraham et al. (2010) failed to measure chlorine element and vanadium, in contrast with the research effort entertained herein. According to Abraham et al. (2010), the most

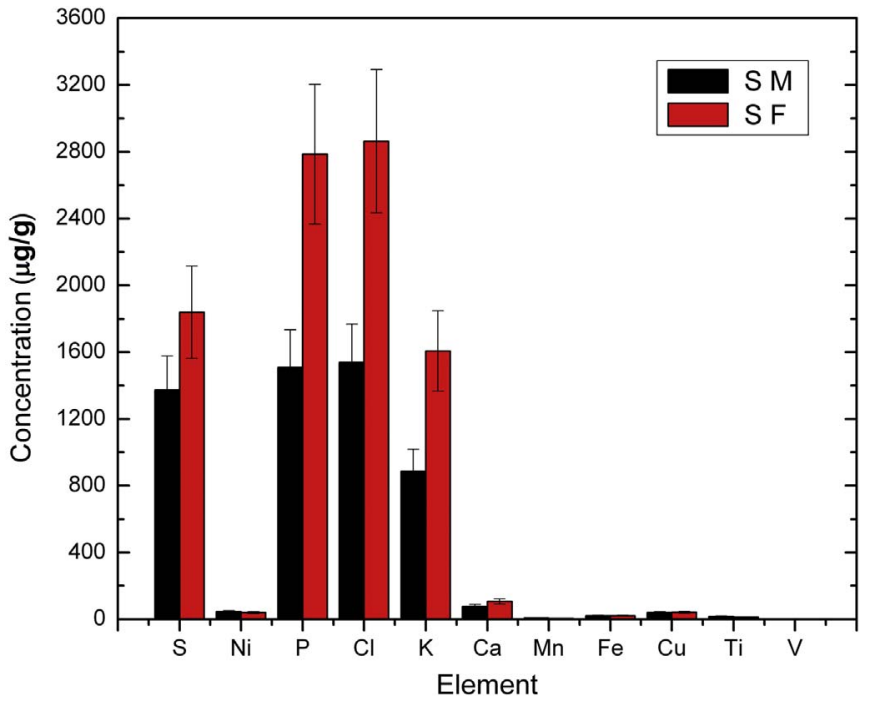

Fig. 8. Bar-graphs with mean concentration $(\mu \mathrm{g} / \mathrm{g})$ of the different chemical elements found in saliva samples from smokers divided by sex. Standard deviation bars are also included (triplicate measurements for fluorescence analyses for each one of 8 smoker female and 8 smoker male individuals). For both groups the quantity of cigarettes smoked per day is $20 \pm 5$ cigarettes/day. Legend: black=SM (smoker male) and red=SF (smoker female). The ANOVA analyses performed for elements $\mathrm{S}, \mathrm{Ni}, \mathrm{P}, \mathrm{Cl}, \mathrm{K}, \mathrm{Ca}, \mathrm{Mn}$, $\mathrm{Fe}, \mathrm{Cu}, \mathrm{Ti}$, and $\mathrm{K}$ produced the following $p$-values: $\mathrm{S}(p=0.04), \mathrm{Ni}(p=0.28), \mathrm{P}(p=0.04)$, $\mathrm{Cl}(p=0.04), \mathrm{K}(p=0.04), \mathrm{Ca}(p=0.03), \mathrm{Mn}(p=0.32), \mathrm{Fe}(p=0.51), \mathrm{Cu}(p=0.29)$, Ti $(p=0.71)$ e V $(p=0.51)$. (For interpretation of the references to color in this figure legend, the reader is referred to the web version of this article.)

Table 1

Mean concentration ( $\mathrm{n}=3$ for fluorescence analyses) and associated standard deviation for the chemical elements found in the saliva of smokers $(n=16)$ and nonsmokers $(n=16)$, divided by sex ( 8 males and 8 females). For both groups, the quantity of cigarettes smoked was $20 \pm 5$ cigarettes/day.

\begin{tabular}{llllll}
\hline Chemical Elements & \multicolumn{2}{l}{ Smokers } & & \multicolumn{2}{l}{ Nonsmokers } \\
\cline { 2 - 3 } \cline { 5 - 6 } \cline { 5 - 6 } & $\begin{array}{l}\text { Male } \\
(\mu \mathrm{g} / \mathrm{g})\end{array}$ & $\begin{array}{l}\text { Female } \\
(\mu \mathrm{g} / \mathrm{g})\end{array}$ & & $\begin{array}{l}\text { Male } \\
(\mu \mathrm{g} / \mathrm{g})\end{array}$ & $\begin{array}{l}\text { Female } \\
(\mu \mathrm{g} / \mathrm{g})\end{array}$ \\
\hline $\mathrm{S}$ & $1371 \pm 205$ & $1839 \pm 275$ & & $1535 \pm 230$ & $326 \pm 49$ \\
$\mathrm{P}$ & $1508 \pm 226$ & $2786 \pm 417$ & & $1733 \pm 260$ & $1927 \pm 289$ \\
$\mathrm{Cl}$ & $1537 \pm 230$ & $2863 \pm 429$ & & $1932 \pm 290$ & $1301 \pm 196$ \\
$\mathrm{~K}$ & $885 \pm 132$ & $1606 \pm 240$ & & $1002 \pm 150$ & $679 \pm 102$ \\
$\mathrm{Ca}$ & $76 \pm 11$ & $105 \pm 15$ & & $71 \pm 11$ & $77 \pm 12$ \\
$\mathrm{Mn}$ & $6 \pm 1$ & $5 \pm 1$ & & $4 \pm 1$ & $5 \pm 1$ \\
$\mathrm{Fe}$ & $20 \pm 3$ & $20 \pm 3$ & & $20 \pm 3$ & $18 \pm 3$ \\
$\mathrm{Cu}$ & $39 \pm 6$ & $41 \pm 6$ & & $41 \pm 6$ & $45 \pm 7$ \\
$\mathrm{Ti}$ & $1 \pm 0.2$ & $2 \pm 0.3$ & & $1 \pm 0.2$ & $1 \pm 0.2$ \\
$\mathrm{Ni}$ & $44 \pm 7$ & $39 \pm 6$ & & $29 \pm 5$ & $38 \pm 6$ \\
\hline
\end{tabular}

significant differences in concentrations of $\mathrm{S}, \mathrm{K}$ and $\mathrm{Ca}$ in the saliva of smokers and nonsmokers could be related to the development of periodontal disease in some patients belonging to the smoker group (Feldman et al., 1983; Haber et al., 1993; Bergström et al., 1994). Finally, one interesting result that was identified in this study, not yet reported in the literature, were the differences found in the saliva of smoker individuals when separated by sex. The data reported herein clearly indicate that smoking seems to be more harmful to the health of women, who smoke, than for men.

\section{Conclusions}

The analysis of saliva by the EDXRF technique showed that there are differences in the composition of saliva of smoker $(n=16)$ individuals $(20 \pm 5$ cigarettes smoked per day for both groups) when compared with the control group (nonsmokers, $n=16$ ). Qualitative results of saliva analysis indicated the presence of the following 


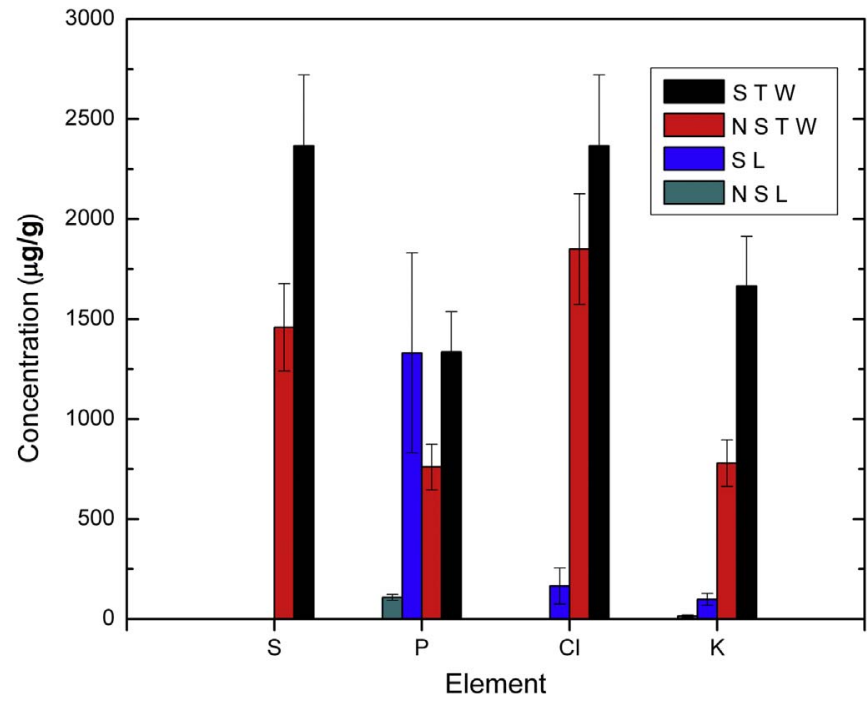

Fig. 9. Bar-graphs with mean concentration $(\mu \mathrm{g} / \mathrm{g})$ of the different chemical elements found in saliva samples from smokers and nonsmokers individuals of both sexes, compared with literature data (Abraham et al., 2010). Standard deviation bars are also included (triplicate measurements for fluorescence analyses for each one of 16 smoker and 16 nonsmoker individuals). Legend: Black=STW (smokers this work); Red=NST W (nonsmokers this work); Blue=SL (smokers literature, Abraham et al., 2010) and Green=NSL (nonsmokers literature, Abraham et al., 2010). (For interpretation of the references to color in this figure legend, the reader is referred to the web version of this article.)

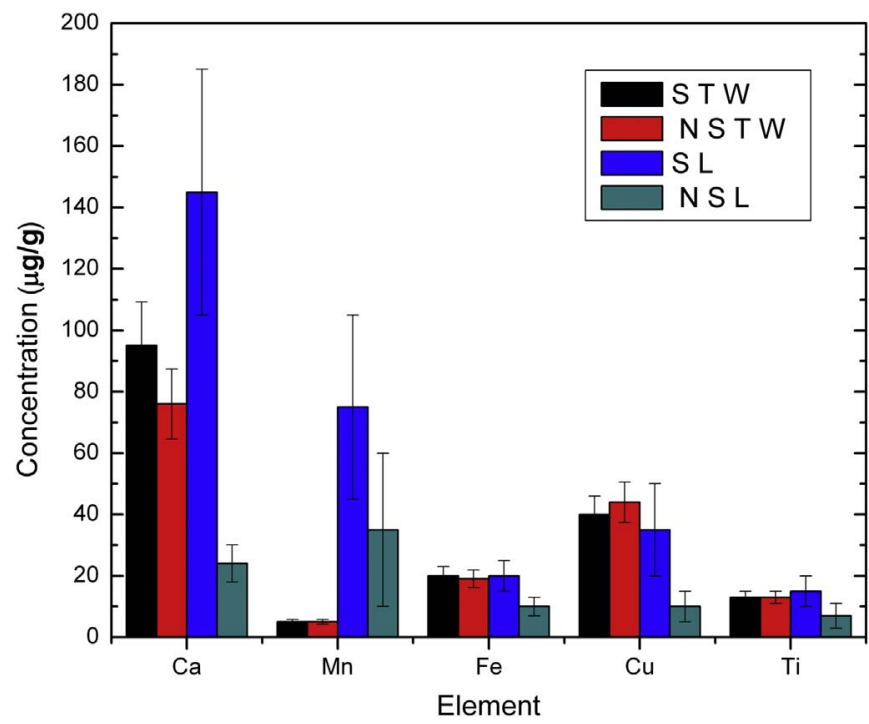

Fig. 10. Bar-graphs with mean concentration $(\mu \mathrm{g} / \mathrm{g})$ of the different chemical elements found in saliva samples from smokers and nonsmokers individuals of both sexes, compared with literature data (Abraham et al., 2010). Standard deviation bars are also included (triplicate measurements for fluorescence analyses for each one of 16 smoker and 16 nonsmoker individuals). Legend: Black=STW (smokers this work); Red=NSTW (nonsmokers this work); Blue=SL (smokers literature, Abraham et al., 2010) and Green=NSL (nonsmokers literature, ABRAHAM et al., 2010). (For interpretation of the references to color in this figure legend, the reader is referred to the web version of this article.)

chemical elements: $\mathrm{S}, \mathrm{Ni}, \mathrm{P}, \mathrm{Cl}, \mathrm{K}, \mathrm{Ca}, \mathrm{Cr}, \mathrm{Mn}, \mathrm{Fe}, \mathrm{Cu}, \mathrm{Ti}$ and V. In a saliva sample from a nonsmoker female individual, it was detected the presence of the element Arsenic at a concentration of $(47 \pm 37) \mu \mathrm{g} / \mathrm{g}$. The highest concentrations for the elements of the smokers were $\mathrm{S}, \mathrm{P}$, $\mathrm{Cl}$ and $\mathrm{K}$, with values above $1000 \mu \mathrm{g} / \mathrm{g}$. The other elements analyzed for smokers were below $100 \mu \mathrm{g} / \mathrm{g}$. The data obtained show that the concentration of the elements found in the saliva tends to be higher for smokers compared to nonsmokers. Our data indicate that major changes occur in the saliva of female smokers $(n=8)$ than in that of males $(n=8)$. The major difference appears in the concentration of the elements $\mathrm{S}, \mathrm{P}, \mathrm{Cl}$ and $\mathrm{K}$, with a significant increase in the concentration of these elements in the saliva of female individuals. When we analyze the concentration of chemical elements $\mathrm{S}, \mathrm{Cl}, \mathrm{K}$ and $\mathrm{Ca}$ in smokers, depending on the time of cigarette use (ranging from 3 to 43 years of smoking), we observe an increasing trend in the concentration of these elements for females and a decrease in the case of males. Analyzing the concentration of the elements $\mathrm{S}, \mathrm{K}, \mathrm{Ni}$ and $\mathrm{Cl}$ present in the saliva of male and female smokers, according to the number of cigarettes smoked per day, it was found that for males, the concentrations tend to decrease as a function of the number of cigarettes smoked, much more than the average decrease observed for women. By comparing the data obtained in this study with literature data (Abraham et al., 2010), a close agreement was noticed with the data reported in the literature for the concentration of elements $\mathrm{K}, \mathrm{Ca}, \mathrm{Fe}, \mathrm{Cu}$ and $\mathrm{Ti}$ for smokers and $\mathrm{Fe}$ and $\mathrm{Ti}$ for nonsmokers, but there are discrepancies in the concentrations of other elements, both for smokers and nonsmokers. Finally, this study provides a strong evidence, not yet reported in the literature, that smoking habits seems to be more harmful for females than for males.

\section{Acknowledgments}

Project funding by Fundação de Amparo à Pesquisa do Estado de São Paulo (FAPESP, São Paulo, Brazil) (FAPESP Refs. no. 2012/ 15651-4 and 2013/03181-6), is hereby gratefully acknowledged. This work also received support from CNPq, National Council for Scientific and Technological Development - Brazil, in the form of Research Productivity (PQ) fellowships granted to Victor M. Balcão (Ref. no. 306113/2014-7) and Marco V. Chaud (Ref. No. 309598/2014-1). The authors have no conflicts of interest whatsoever to declare.

\section{References}

Abraham, J.A., Sánchez, H.J., Valentinuzzi, M.C., Grenón, M.S., 2010. Influence of smoking on the elemental composition of oral fluids: a TXRF approach. X-Ray Spectrom. 39 (6), 372-375.

Bergström, J., Preber, H., 1994. Tobacco use as a risk factor. J. Periodontol. 65 (5), $545-550$.

Castilhos, N.D.B., Melquiades, F.L., Thomaz, E.L., Bastos, R.O., 2015. X-ray fluorescence and gamma-ray spectrometry combined with multivariate analysis for topographic studies in agricultural soil. Appl. Radiat. Isot. 95, 63-71.

Cleto, D.A.M., 2013. Análise de Saliva e do Fluído Sulco Gengival pelo Método de Fluorescência de Raios-X por Reflexão Total, Dissertação de Mestrado. Universidade Estadual de Londrina, Londrina, PR, 85.

Edgar, W.M., 1992. Saliva: its secretion, composition and functions. Br. Dent. J. 172 (8), $305-312$.

Feldman, R.S., Bravacos, J.S., Rose, C.L., 1983. Association between smoking different tobacco products and periodontal disease indexes. J. Periodontol. 54 (8), 481-487.

Gunnerbeck, A., Bonamy, A.K.E., Wikström, A.K., Granath, F., Wikström, R., Cnattingius, S., 2014. Maternal snuff use and smoking and the risk of oral cleft malformations - a population-based cohort study. PloS One 9, 1.

Haber, J., Wattles, J., Crowley, M., Mandell, R., Joshipura, K., Kent, R., 1993. Evidence for cigarette smoking as a major risk factor for periodontitis. J. Periodontol. 64 (1), $16-23$.

Kajiya, E.A.M., Campos, P.H.O.V., Rizzutto, M.A., Appoloni, C.R., Lopes, F., 2014. Evaluation of the veracity of one work by the artist Di Cavalcanti through nondestructive techniques: XRF, imaging and brush stroke analysis. Radiat. Phys. Chem. 95, 373-377.

Lima, F.O., Ramalho, M.J.P., Rummlerd, M.C.O., Rodriguez, T.T., 2008. Hipotiroidismo altera secreção e composição salivar em ratos sépticos. Rev. Odont. Ciên 23 (1), 23-27.

Marguí, E., Queralt, I., Hidalgo, M., 2009. Application of X-ray fluorescence spectrometry to determination and quantitation of metals in vegetal material. Trends Anal. Chem. 28 (3), 362-372.

Melquiades, F.L., Almeida, E., Peres, J.A., Smuczek, B., Wouk, L.C., 2011. Análise de metais em sangue de bovinos e no ambiente de criação de bovinos por EDXRF. Rev. Ciên. Exa. Nat. 13 (1), 9-21.

Nascimento, F.V., 1999. Técnicas Analíticas Nucleares de Fluorescência de Raios-X por Dispersão em Energia (EDXRF) e por Reflexão Total (TXRF), Private communication, CENA.

Parreira, P.S., 2006. Metodologia de EDXRF e Aplicações com um Sistema Portátil. Publicação Técnica - Laboratório de Física Nuclear Aplicada. Universidade Estadual de Londrina, Londrina, PR, 17.

Rang, H.P., Dale, M.M., Ritter, J.M., Flower, R.J., Henderson, G., 2007. Rang \& Dale - 
Farmacologia 7th ed. Elsevier, Rio de Janeiro.

Sánchez, H.J., Valentinuzzi, M.C., Grenón, M., Abraham, J., 2008. Total reflection X-ray fluorescence analysis of oral fluids of women affected by osteoporosis and osteopenia. Spectrochim. Acta B 63 (12), 1485-1488.

WHO - World Health Organization, 2016. Questions about tobacco research. Available in: 〈http://www.who.int/tobacco/publications/surveillance/tqs_po_final.pdf) (accessed 02.02.16).
Zamboni, C.B., Metairon, S., Kovacs, L., Macedo, D.V., Rizzutto, M.A., 2015.

Determination of $\mathrm{Fe}$ in blood using portable X-ray fluorescence spectrometry: an alternative for sports medicine. J. Radioanal. Nucl. Chem. 1, 1.

Zamburlini, M., Pejović-Milić, A., Chettle, D.R., Webber, C.E., Gyorffy, J., 2007. In vivo study of an X-ray fluorescence system to detect bone strontium non-invasively. Phys. Med. Biol. 52 (8), 2107-2122. 